\author{
Espacio y Desarrollo No 31, 2018, pp. 33-57 (ISSN 1016-9148) \\ https://doi.org/10.18800/espacioydesarrollo.201801.002
}

\title{
Adaptación de un Índice de Vulnerabilidad Costera - IVC PARA EL LITORAL PERUANO: UN ESTUDIO DE CASO
}

\author{
Gustavo Rondón Ramírez \\ Pontificia Universidad Católica del Perú \\ grondon@pucp.edu.pe
}

Carlos Tavares Corrêa

Centro de Investigación en Geografía Aplicada - CIGA,

Pontificia Universidad Católica del Perú ctavare@pucp.pe

Fecha de recepción: 7 de marzo de 2018 Fecha de aceptación: 10 de junio de 2018

\section{Resumen}

La presente investigación evalúa la vulnerabilidad a la erosión en la costa peruana bajo un escenario de aumento del nivel del mar como producto del cambio climático. Con este propósito, se construyó un Índice de Vulnerabilidad Costera - IVC que integra variables físicas (geomorfología, tipo de playa, pendiente y variación de la línea de costa) y variables antrópicas (usos del suelo, ancho de playa y ocupación de la costa). El IVC se utilizó para analizar la costa de la provincia de Pacasmayo (región La Libertad, Perú), con datos obtenidos por levantamientos de campo y teledetección, incorporados a un Sistema de Información Geográfica - SIG. El estudio identificó que el 5,8\% del litoral presentaba una vulnerabilidad baja, el 82,9\% vulnerabilidad media y el $11,3 \%$ vulnerabilidad alta. Al considerar únicamente las variables físicas, la alta vulnerabilidad aumenta considerablemente (32\%). En cambio, si solo se toman en cuenta las variables antrópicas, la alta vulnerabilidad disminuye $(7,4 \%)$.

Palabras clave: cambio climático, aumento del nivel del mar, Índice de Vulnerabilidad Costera, provincia de Pacasmayo

\section{Adapting a Coastal Vulnerability Index - CVI for the Peruvian shoreline: a study case}

\section{Abstract}

This study evaluates erosion vulnerability in the Peruvian coastline under a sea-level rise scenario in a Climate Change context. For this purpose, a Coastal Vulnerability Index CVI was developed, which integrates physical variables (geomorphology, beach type, beach 
slope, and shoreline changes) and human-related variables (land use, beach width, and coastal settlement). The CVI was used to analyze the coastline of the Pacasmayo province (La Libertad region, Peru), with data obtained from field surveys and remoting sensing, on a geographic information system (GIS). The study found that $5.8 \%$ of the coastline showed a low vulnerability, $82.9 \%$ medium vulnerability, and $11.3 \%$ high vulnerability. When considering physical variables solely, high vulnerability increases considerably $(32 \%)$. Whereas, if only human-related variables are taken into account, high vulnerability decreases (7.4\%).

Keywords: climate change, sea-level rise, Coastal Vulnerability Index, Pacasmayo

\section{Adaptation d'un indice de vulnérabilité côtière (IVC) pour la côte péruvienne: une étude de cas}

\section{RÉSUMÉ}

La présente étude évalue la vulnérabilité à l'érosion de la côte péruvienne dans un scénario d'élévation du niveau de la mer dans un scenario de changement climatique. À cette fin, un Indice de Vulnérabilité Côtière (IVC) a été construit, intégrant des variables physiques (géomorphologie, type de plage, pente et variation de la ligne de côte) et anthropiques (utilisation des sols, largeur des plages et occupation des sols). L'IVC a été utilisée pour analyser la côte de la province de Pacasmayo (région de La Libertad, Pérou), avec des données obtenues par des travails sur le terrain et la télédétection, incorporées dans un système d'information géographique (SIG). L'étude a identifié que 5,8\% du littoral présentait une vulnérabilité faible, $82,9 \%$ une vulnérabilité moyenne et $11,3 \%$ une vulnérabilité élevée. En ne considérant que les variables physiques, la grande vulnérabilité augmente considérablement (32\%). En revanche, si l'on ne prend en compte que les variables anthropiques, la forte vulnérabilité diminue $(7,4 \%)$. Mots-clés: changement climatique, élévation du niveau de la mer, Index de Vulnérabilité Côtier, province de Pacasmayo

\section{INTRODUCCIÓN}

Hace algunas décadas, Bird (1985) identificó que el 70\% de las playas arenosas del planeta sufrían procesos de erosión. Más recientemente, Zhang, Douglas y Letherman (2004) reconocieron que, si bien la estabilidad de las playas se ve afectada por la presencia de estructuras costeras a escala local, los procesos erosivos en el mundo responden al aumento en el nivel del mar y a la intensificación de tormentas oceánicas debido el calentamiento global y al cambio climático (IPCC, 2014). Durante el presente siglo, el nivel del mar seguirá en aumento y, probablemente, superará las tasas ya registradas en la primera década del siglo XXI, que a escala global superan los 3 milímetros anuales (Church y White, 2006 y 2011). Según el Ministerio de Ambiente de España (2006), el posible aumento del nivel del mar y pequeños cambios en el oleaje pueden amenazar la estabilidad de los ambientes costeros, tales como las playas, los estuarios, los campos 
de dunas y las obras marítimas. A lo descrito anteriormente se debe sumar que, en la actualidad, más del $65 \%$ de la población vive en las zonas costeras del planeta, que son muy vulnerables a los potenciales impactos de cambio climático (FAO, 2012).

Según la Cepal (2012), los estudios del cambio climático en las costas se ejecutan en tres escalas: una global, donde el detalle de la información inicial y los resultados alcanzados son de baja resolución (escala nacional o internacional); una regional, centrada en los planes regionales y cuya información y resultados son de nivel intermedio, y finalmente, una local, donde se elaboran los planes locales y tienen un alto nivel de detalle de la información y los resultados presentados. Es justamente este reto lo que ha motivado en las últimas décadas a desarrollar índices que permitan evaluar la vulnerabilidad de las zonas costeras en el mundo. El índice de vulnerabilidad costera - IVC es uno de los más difundidos y aplicados a lo largo de las costas del mundo.

A partir de los trabajos de Gornitz (1991) y Gornitz, Beaty y Daniels (1997), donde se introdujo el IVC como herramienta para el análisis de las características físicas de la costa y el impacto poblacional cuando se ocupan estos espacios, diversos estudios similares han sido realizados en el mundo. Entre estos, se pueden mencionar los de Gorokovich, Leiserowitz y Dugan (2014), González, Haces y Rangel (2010), Ramírez (2010), Pendleton. Hammer-Klose, Thieler y Williams (2004) y Kokot, Codignotto y Elissondo (2004) en América; a Ojeda, Álvarez, Martín y Fraile (2009), Doukakis (2005) y McLaughlin, McKenna y Cooper (2002) en Europa; a Appeaning (2013) en África; a Sarajit, Nakhapakorn, Jirakajohnkool, Tienwong y Pansuwan (2015), Dwarakish et al. (2009) y Nageswara et al. (2008) en Asia, y a Aboudha y Woodroffe (2006) en Oceanía.

El IVC (Gornitz, 1991; Gornitz et al., 1997) se basó inicialmente en el empleo de variables netamente físicas (topografía, geología, geomorfología, variación relativa del nivel del mar, variación de la línea de costa, amplitud de marea y altura del oleaje). Más recientemente, y a raíz de los nuevos enfoques sobre la vulnerabilidad (ej.: McLaughlin et al., 2002; Green y McFadden, 2007), se ha procurado combinar las variables físicas con variables antrópicas o sociales (uso del suelo, densidad poblacional, distancia de la línea de costa, etc.), tal como lo realizaron Torresan, Critto, Rizzi y Marcomini (2012), la Consejería de Medio Ambiente de Andalucía (2011) o la Agencia Europea de Medio Ambiente (2011), entre otros.

Otro aspecto importante se refiere a la definición de la unidad de análisis. Un grupo de autores (ej.: Gornitz et al., 1997; Hammar-Klose, Pendleton, Thieler y Williams, 2003; Siva, Chandramouli, Gokul, Mangala y Saravanavel, 2015, etc.) utilizaron unidades de análisis basadas en distancias fijas medida en metros, kilómetros o grados. Cada una de las variables fueron analizadas en esos segmentos fijos y el resultado del IVC se presenta de manera espacial dentro de cada segmento previamente establecido. El otro grupo de autores (ej.: Appening, 2013; Doukakis, 2005; Jiménez, 2013 , etc.) utilizaron como unidad de análisis un segmento de costa definido según 
las características geomorfológicas (arcos de playas entre puntas rocosas), hidrográficas (límite de cuencas), ambientales o políticas (límites administrativos). En cada una de estas unidades preestablecidas los autores mencionados estimaron valores de vulnerabilidad para a cada una de las variables analizadas. Esta valoración se basó en calificativos como «bajo», «medio» o «alto», que generalmente son sustituidos por números para aplicar la ecuación del IVC. En cuanto a la ecuación, pese a que varios autores aún mantienen la ecuación original de análisis de la vulnerabilidad (raíz cuadrada del producto del valor de la vulnerabilidad de cada variable sobre el número total de variables), diversos autores (Doukakis, 2005; Gonzales et al., 2010; Ronald, 2012) han probado con variaciones a la ecuación original.

En el Perú, aproximadamente el $60 \%$ de la población total del país vive a lo largo de una franja costera con poco más de $3000 \mathrm{~km}$ de extensión (Novoa, 2007). Esta ocupación no es homogénea, sino se concentra en grandes centros urbanos de la costa central y norte, como Lima, Callao, Pisco, Chimbote, Trujillo, Paita o Talara, además de caletas de pescadores y balnearios. A esta población se debe sumar la importancia del borde costero por la gran diversidad de usos que desarrolla y que pueden verse afectados por el aumento del nivel del mar. Pese a la importancia de la zona costera para el país, un número limitado de estudios han sido realizados con el propósito de evaluar la vulnerabilidad costera frente el aumento del nivel del mar. Para un escenario de aumento del nivel del mar entre 0,3 y 1 metro, Teves et al. (1996a) han evaluado que el distrito de La Punta (Callao) sería muy afectado por la erosión marina y recomendaron medidas de protección con espigones y rompeolas. En otro estudio, Teves, Laos, Carrasco, San Román y Clemente (1996b) consideraron que el 30\% de la costa peruana será afectada por el aumento del nivel del mar. Ciudades como Puerto Pizarro, Chimbote, Pisco e Ilo correrían peligro de inundación y más de 6 millones de turistas internos serían perjudicados. Más recientemente, Aguilar (2015) y Tejada (2017) han aplicado por primera vez el IVC en distritos de costa peruana como Asia y Pucusana, donde integraron variables físicas y socioeconómicas y las analizaron a partir de unidades homogéneas previamente establecidas.

Pese a estas experiencias iniciales, la aplicación metodológica del IVC se encuentra todavía en desarrollo en la costa peruana con el fin de obtener resultados más precisos en cuanto a la predicción de la vulnerabilidad frente a la erosión costera. Esta problemática motivó la elección de una provincia costera: la provincia de Pacasmayo, en la región de La Libertad, como un piloto para la construcción y aplicación de un IVC local capaz de integrar las variables físicas y antrópicas de manera que permita determinar la vulnerabilidad de la mencionada provincia. A continuación, esta investigación presentará brevemente la zona de estudio, describirá de manera detallada el enfoque metodológico aplicado y mostrará los principales resultados obtenidos, seguido de una discusión sobre aquellos, para finalmente cerrar con las conclusiones principales. 


\section{Área de estudio}

La provincia de Pacasmayo se encuentra ubicada en la región La Libertad, en el norte del Perú. Limita con las provincias de Chepén - La Libertad, Ascope - La Libertad y Contumazá - Cajamarca, y al oeste con el océano Pacífico (figura 1). La provincia tiene un área aproximada de $1130 \mathrm{~km}^{2}$, fue fundada en 1864 y quedó conformada de manera definitiva en 1984 con la separación de la provincia de Chepén. El litoral de la provincia de Pacasmayo se extiende por casi 700 kilómetros y está integrada por cuatro distritos: San Pedro de Lloc, Guadalupe, Jequetepeque y Pacasmayo. La capital de la provincia se ubica en el distrito de San Pedro de Lloc, el cual es la sede políticoadministrativa y concentra a las dependencias del sector público, además de tener una agricultura dedicada principalmente al cultivo de arroz, una actividad avícola en crecimiento y una creciente actividad comercial. El distrito de Pacasmayo es el centro financiero, comercial y de servicios de la provincia, con una actividad pesquera limitada por falta de infraestructura portuaria y equipamiento y con una actividad turística concentrada en la bahía; el distrito de Guadalupe tiene la mayor parte de su superficie dedicada a la producción agropecuaria, especialmente arroz y con una importante agroindustria en molinos de arroz, y finalmente en el distrito de Jequetepeque predomina la agricultura —en especial arroz- y una importante producción agroindustrial de lácteos y avicultura con alcance regional y nacional (Municipalidad Provincial de Pacasmayo, 2008).

En lo que respecta al aspecto geológico y geomorfológico, se observa la presencia de niveles de terrazas aluviales (Teves, 1982) que en el litoral se presentan como acantilados con alturas superiores a 20 metros (T3) y predominan en el sector norte del área de estudio. Hacia el sur de la desembocadura del río Jequetepeque, los acantilados tienden a disminuir con alturas inferiores entre 20 metros y 4 metros (T2). Los acantilados desaparecen completamente en la llanura aluvial del Jequetepeque y en el sector de Santa Elena, al sur de El Milagro. Teves (1982) señala que los sedimentos litorales constituyen playas continuas casi a todo lo largo de la provincia, las arenas de color gris claro predominan en la mayor parte de la línea de costa y solo se ven interrumpidas por cordones litorales de cantos rodados o la presencia de acantilados «vivos», como al norte de la desembocadura del Jequetepeque y en el sector comprendido entre Pacasmayo y el balneario El Milagro.

En el sector de Santa Elena, las playas son principalmente de arenas finas y muy finas y están sujetas al transporte por el viento, dando lugar a la formación de mantos eólicos que alcanzan dimensiones importantes al sur y este de San Pedro de Lloc, internándose hacia el continente para constituir las dunas del tipo sombras al este del cerro Calera y dejando a manera de pinceladas blanquecinas sobre los cerros rojizos, las huellas a su tránsito hacia el interior (Teves, 1982). Tavares Corrêa (2004) reconoce 
la presencia de dos familias de dunas en el litoral de Santa Elena: la familia de las parabólicas, asociadas a la vegetación, que corresponde a la duna litoral, estabilizada con verdolaga (Sesuvium portulacastrum L.), las cunetas de deflación y parabólicas estabilizadas con grama salada (Distichilis spicata (L.) Greene); y, por la familia de las barjanes, libres de vegetación, que avanzan hacia el interior o se acumulan en la forma de dunas complejas a barlovento de cerros o acantilados "muertos" de baja altura esculpidos sobre la terraza T2.

El clima de la provincia es templado, las lluvias son mínimas y generalmente se presentan entre los meses de diciembre a marzo (CESEL Ingenieros, 2009). Los vientos, que podrían ser considerados un factor erosivo para los suelos, constituyen un gran recurso natural para generar energía eólica para diferentes usos (Municipalidad Provincial de Pacasmayo, 2008). En cuanto a la hidrografía, si bien existen algunas quebradas intermitentes - como la Quebrada Olitares, cerca de la ciudad de Pacasmayo, o la de Cupisnique y algunas lagunas como el Hornito o el Muerto-, la red hidrográfica que forma el río Jequetepeque es la más importante de la provincia tanto hidrográfica como hidrológicamente.

\section{Metodología}

La primera decisión metodológica que enfrentó esta investigación fue la elección de la unidad de análisis para la aplicación del análisis de las variables. En este punto hay dos posiciones muy marcadas. Un grupo de autores (como Gornitz et al., 1997; Hammar-Klose et al., 2003; Siva et al., 2015, etc.) utilizan una unidad de análisis fija basada en una distancia medida en metros, kilómetros o grados. Esto quiere decir que las variables utilizadas son analizadas en esos segmentos fijos y el resultado del IVC se mostrará de manera espacial también dentro de cada segmento previamente definido. El otro grupo de autores (como Appening, 2013; Doukakis, 2005; Jiménez, 2013, etc.) utilizan como unidad de análisis un segmento de costa definido por alguna característica geomorfológica (playas entre puntas rocosas), hidrográfica (límites de las cuencas), ambiental o política (límites administrativos). Es en estas unidades, definidas por las características antes mencionadas, donde los autores analizan las variables y aplican su ecuación.

Con todo el abanico de posibilidades acerca de las variables, ecuaciones y unidades de análisis posibles, se tomaron las decisiones sobre cómo aplicar el IVC en la provincia de Pacasmayo. Con este propósito, la disponibilidad de datos ha jugado un rol esencial en la selección de las variables relevantes para discriminar el litoral de la provincia. Así, se han seleccionado siete variables que pueden ser divididas en dos grupos: las variables físicas y las variables antrópicas (tabla 1). 


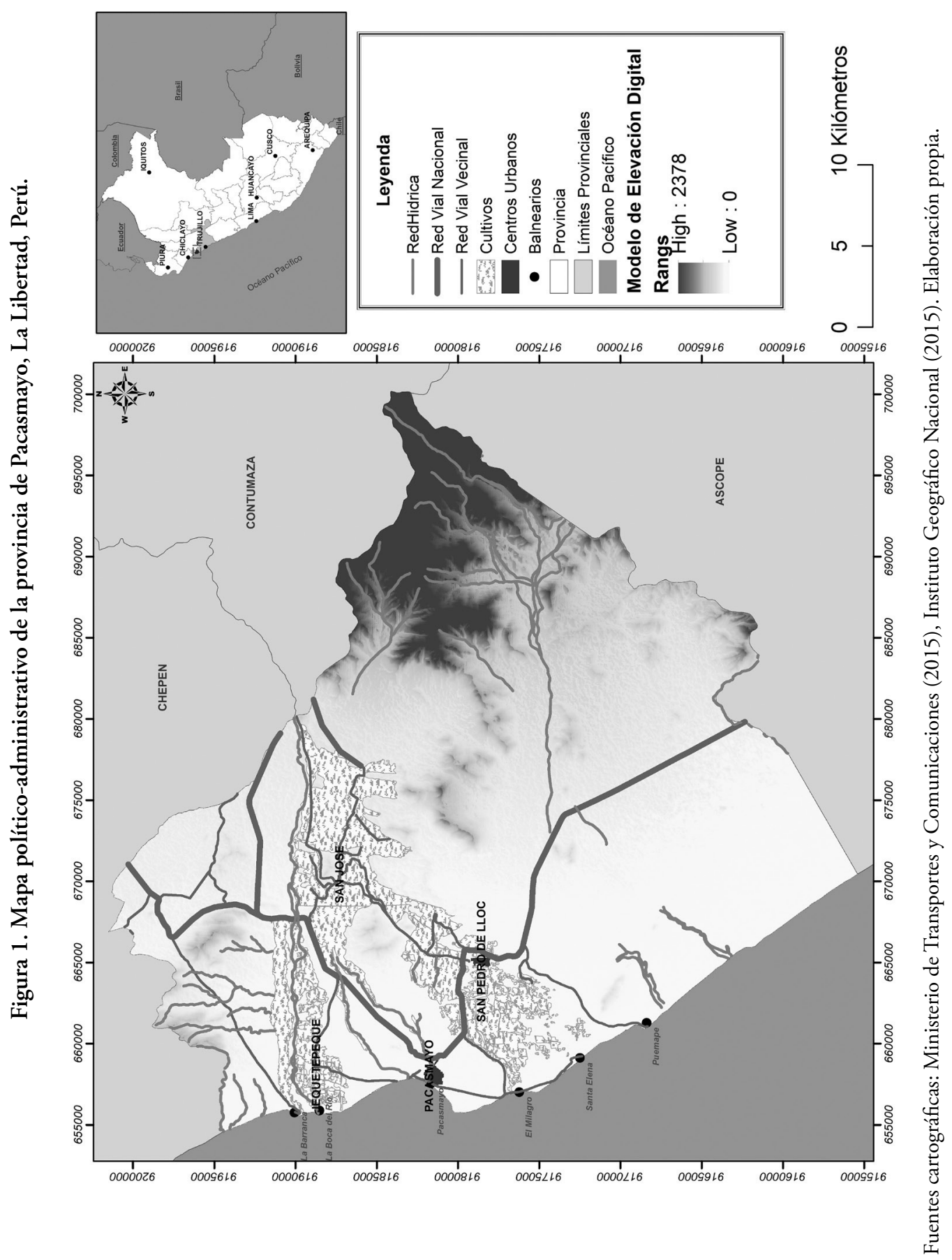


Respecto de la variable "geología-geomorfología», las categorías fueron definidas mediante el trabajo de campo realizado (recorrido a lo largo del borde costero de la provincia) y mapas geológicos a escala provincial, lo que permitió identificar geoformas locales como los acantilados «muertos» y «vivos», llanuras fluvio-marinas o dunas litorales, playas de bolsillo, etc. Respecto de la variable "pendiente de la playa», es importante mencionar que se levantó la pendiente gracias a perfiles de playa (veinticinco en total, en distintos años), lo que permitió interpolar esa información para toda la provincia. La variable «tipo de playa» también fue mapeada durante el levantamiento de perfiles de playa y complementada mediante el análisis de las imágenes proporcionadas por el software libre Google Earth. Por su parte, la variable «variación de la línea de costa» fue realizada gracias a la aplicación de la extensión Digital Shoreline Analysis System - DSAS de la USGS. Para esto, fue necesario georreferenciar mapas a escala 1/25 000 del año 1962, fotos aéreas de escala 1/20 000 del año 1980 e imágenes satelitales de los años 2003, 2011 y 2013 (para mayores referencias, revisar Tavares y Rondón, 2015).

Con respecto a la variable «ancho de playa», si bien podría entenderse como una variable física en el sentido estricto debido a las categorías que delimitan su nivel de vulnerabilidad basadas en la Ley de Playas del Perú (ley 26856), esta entra en la categoría de variable antrópica. Para poder obtener este valor, también se utilizaron los datos levantados en los perfiles de playa, donde en casi la totalidad de casos se realizó el perfil tomando como punto de partida del perfil una infraestructura humana. Luego, al igual que en la variable "pendiente de la playa», se realizó una interpolación para tener valores para todo el borde costero provincial.

La variable «usos del suelo», por su parte, más allá de tener una referencia en los distintos recorridos realizados en la provincia, se clasificó mediante el uso de imágenes satelitales, identificando los grandes usos del suelo costero. Finalmente, la variable «ocupación de la costa» resume o condensa distintas variables, como el tamańo de la población que ocupa la costa, las actividades que se realizan, la función administrativa que cumple, la infraestructura asentada, etc.

Las unidades de análisis fueron trabajadas de una manera similar a los trabajos como los de Merlotto, Bértola y Piccolo (2011) y Ramírez (2010), que pueden servir como ejemplos comparativos. Esta metodología tiene como principio que será cada variable la que determine la vulnerabilidad de la costa, quedando segmentada según su característica. Esto refuerza el objetivo de identificar la vulnerabilidad de la costa a una escala local, sin forzar categorías ni unidades de análisis.

Por esa razón, como se puede apreciar en la tabla 1, a diferencia de la mayoría de autores, no se han clasificado las variables en cinco categorías según su vulnerabilidad, sino que se ha optado por tener solo tres categorías: «bajo», «medio» y «alto». En otras investigaciones, como las de McLaughlin et al. (2002); Ronald (2012); Torresan et al. 
(2012) y Sousa, Siegle y Gonsalez (2013), se aplica también una calificación distinta de las cinco clases de vulnerabilidad.

Tabla 1. Matriz de variables físicas y antrópicas utilizadas para el área de estudio.

\begin{tabular}{|l|l|l|l|}
\hline Variables & Bajo (1) & Medio (2) & Alto (3) \\
\hline $\begin{array}{l}\text { Geología- } \\
\text { geomorfología }\end{array}$ & $\begin{array}{l}\text { Acantilado muerto } \\
\text { Punta Rocosa }\end{array}$ & $\begin{array}{l}\text { Acantilado vivo } \\
\text { Llanura de cordón litoral }\end{array}$ & $\begin{array}{l}\text { Playa de bolsillo } \\
\text { Llanura fluvio-marina }\end{array}$ \\
\hline Tipo de playa & Playa de canto & Playa mixta & $\begin{array}{l}\text { Playa de arena } \\
\text { Playa de biodetritos }\end{array}$ \\
\hline Pendiente $\left(^{\circ}\right)$ & $\begin{array}{l}\text { Entre } 6^{\circ} \text { y } 9^{\circ} \\
\text { Mayor a } 9^{\circ}\end{array}$ & Entre $3^{\circ}$ y $6^{\circ}$ & Menor a $3^{\circ}$ \\
\hline $\begin{array}{l}\text { Variación de la } \\
\text { línea de costa } \\
(\mathrm{m} / \text { ańo })\end{array}$ & Mayor a $0.30 \mathrm{~m} /$ año & $\begin{array}{l}\text { Entre } 0.30 \mathrm{~m} / \text { año y }-0.30 \\
\text { m/ańo }\end{array}$ & Menor a -0.30 m/año \\
\hline $\begin{array}{l}\text { Ancho de playa } \\
(\mathrm{m})\end{array}$ & Mayor a $250 \mathrm{metros}$ & Entre 250 y $51 \mathrm{metros}$ & Menor a 50 metros \\
\hline $\begin{array}{l}\text { Usos del suelo } \\
\text { costero }\end{array}$ & $\begin{array}{l}\text { Sin uso } \\
\text { Uso agrícola } \\
\text { Uso recreacional }\end{array}$ & $\begin{array}{l}\text { Uso residencial Medio- } \\
\text { Bajo } \\
\text { Uso residencial Alto- } \\
\text { Medio }\end{array}$ \\
\hline $\begin{array}{l}\text { Ocupación de } \\
\text { la costa }\end{array}$ & $\begin{array}{l}\text { Sin ocupación } \\
\text { Ocupación mixta } \\
\text { (cultivos, deportes } \\
\text { náuticos) }\end{array}$ & $\begin{array}{l}\text { Balneario estacional } \\
\text { residencia }\end{array}$ & Puerto \\
\hline
\end{tabular}

\section{Cálculo del IVC para la provincia de Pacasmayo}

El paso final para hallar el IVC en la provincia de Pacasmayo fue definir el método para lograr el resultado total de la vulnerabilidad. En este caso, se optó por una suma de los valores de vulnerabilidad de cada variable representada con una letra (ver ecuación 1). Para esto, se volvió a formato Raster (.tif) cada una de las líneas segmentadas. Una vez realizado esto, y siempre trabajando en el software ArcMap 10.1 se utilizó la herramienta «Raster Calculator», lo que nos permitió realizar la sumatoria. Una vez realizado esto, se dividieron en rangos los valores de la vulnerabilidad total para mantener las tres categorías de análisis.

$$
\text { IVC }=a+b+c+d+e+f+g
$$

La división de los intervalos de clase para la vulnerabilidad se realizó teniendo en cuenta que, si el valor mínimo posible para todas las variables fuera igual a 1, la sumatoria mínima sería 7; por su parte, si cada variable tuviera el máximo valor, que es 3, el valor máximo del índice sería 21. Esta misma ecuación se aplicó para las cuatro 
variables físicas y las tres variables antrópicas. Evidentemente, los valores totales de la vulnerabilidad física y antrópica serán menores a la vulnerabilidad total (ya no se suman siete variables, sino cuatro para las físicas y tres para las antrópicas), pero la forma de clasificación de la vulnerabilidad sigue la misma lógica y se resume en la tabla 2.

Tabla 2. Rangos y valores para el cálculo del IVC en la provincia de Pacasmayo aplicando la ecuación 1.

\begin{tabular}{|l|c|c|c|}
\hline Vulnerabilidad & IVC total & IVC físico & IVC antrópico \\
\hline Baja & 7 a 11 & 4 a 6 & 3 a 5 \\
\hline Media & 12 a 16 & 7 a 9 & 6 y 7 \\
\hline Alta & 17 a 21 & 10 a 12 & 8 y 9 \\
\hline
\end{tabular}

\section{Resultados}

En la variable "geología-geomorfología» se han identificado seis categorías morfológicas y morfodinámicas: acantilados muertos (ubicados, por ejemplo, al norte y al sur de la bahía de Pacasmayo), acantilados vivos (al norte del balneario La Barranca o al norte de El Milagro), llanura fluvio-marina (en la desembocadura del río Jequetepeque), llanura de cordón litoral (al sur de Puémape), punta rocosa y playa de bolsillo (ambas en la zona de Puémape). En la variable «pendiente» se han identificados 4 categorías: zonas de pendiente menor a $3^{\circ}$ (principalmente al sur de la provincia), pendientes entre $3^{\circ}$ y $6^{\circ}$ (al norte de la desembocadura del río Jequetepeque), pendientes entre $6^{\circ}$ y $9^{\circ}$ (al norte y sur de Pacasmayo) y pendientes mayores a $9^{\circ}$ (al sur de El Milagro).

La variable «tipo de playa» ha permitido identificar cuatro categorías: playas de arena que predominan en la provincia, playas de canto (al norte de La Barranca), playas mixtas (en la desembocadura del Jequetepeque debido a la estacionalidad del aporte de sedimentos) y playas de biodetritos (en Puémape). La última variable física, «variación de la línea de costa», se clasificó en tres categorías basadas en la desviación estándar de las tasas de variación obtenidas una vez corrido el análisis con el DSAS: desde el balneario Santa Elena hasta el norte de la provincia predomina el retroceso de la línea de costa (menor a $-0,30 \mathrm{~m} / \mathrm{anno}$ ) y al sur del mismo balneario se mezclan zonas de estabilidad (entre $-0,30$ y +0,30 m/año) y zonas de avance en dirección al mar $(+0,30 \mathrm{~m} / \mathrm{año})$. Todas estas variables físicas se pueden apreciar en la figura 2. 
Figura 2. Mapa de variables físicas.

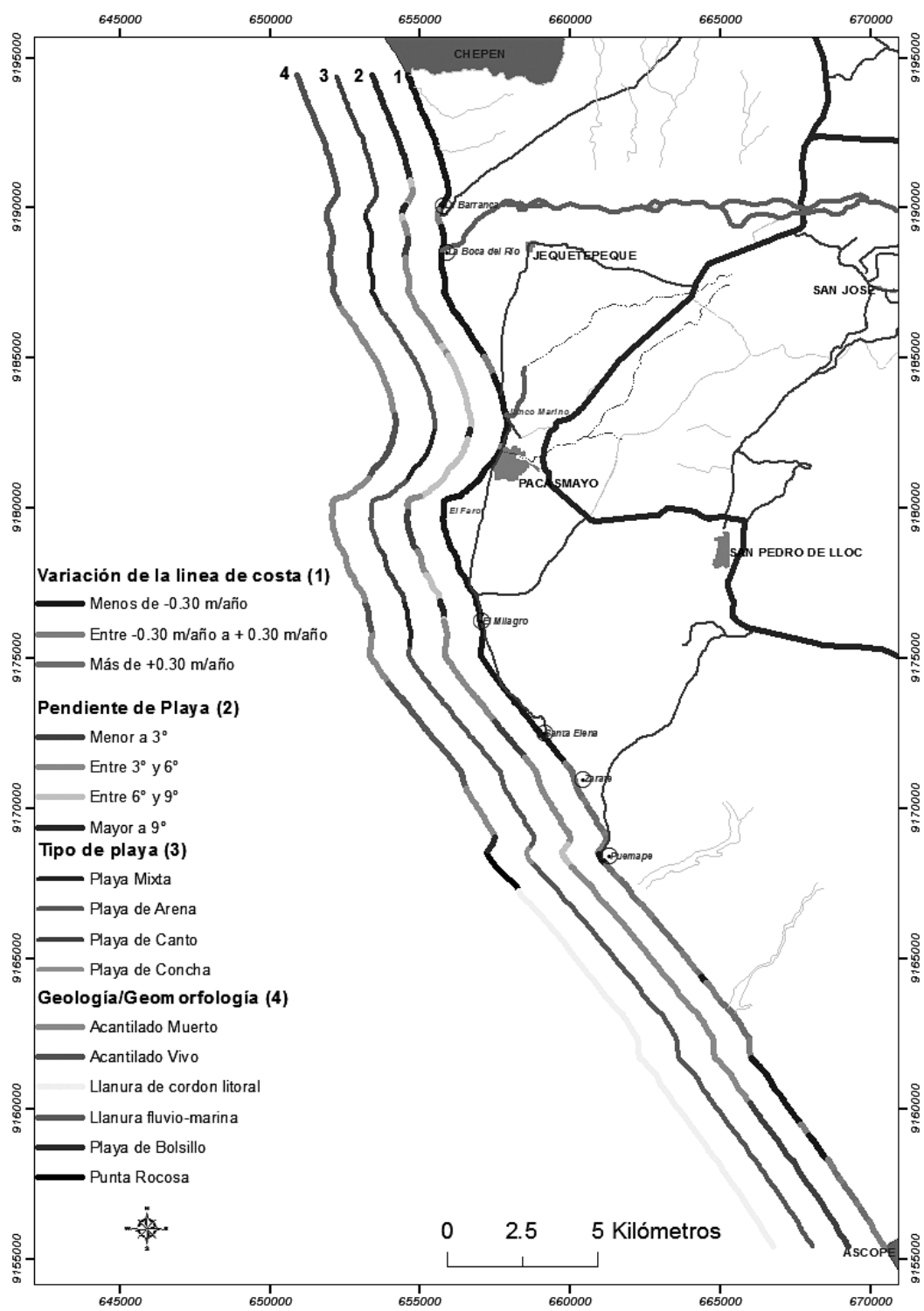

Fuentes cartográficas: Ministerio de Transportes y Comunicaciones (2015), Instituto Geográfico Nacional (2015). Elaboración propia.

Respecto de las variables antrópicas, se ve que en «ancho de playa», las playas con infraestructuras instaladas a menos de 50 metros predominan en zonas como el puerto de Pacasmayo, el norte de La Barranca; en zonas como el sur de Pacasmayo, 
Santa Elena o Puémape, que tienen rangos entre 51 y 250 metros, mientras que al sur de la provincia las distancias sobrepasan los 250 metros. Estas categorías se basan en las divisiones que señala la Ley de Playas. La variable «uso del suelo» presenta cinco categorías: zonas de residencia medio-alta (puerto de Pacasmayo), zonas de residencia medio-bajo (los balnearios a lo largo de la provincia), zonas agrícolas (desembocadura del Jequetepeque), zonas de uso recreacional (zona de El Faro) y zonas sin uso (las superficies donde solo está presente el desierto costero).

Finalmente, en la variable «ocupación de la costa» se han identificado cinco categorías: la ocupación del puerto de Pacasmayo (alta densidad de población, actividad económica dinámica, etc.), balnearios estacionales que se activan en verano (Puémape, El Milagro), balnearios segunda-residencia que, si bien se activan, en verano tienden a tener una población constante (Santa Elena, La Barranca), ocupación mixta como cultivos o deportes náuticos (al sur y norte de la mayoría de balnearios) y zonas sin usos (principalmente al sur de la provincia). La figura 3 nos muestra las variables antrópicas antes descritas.

Una vez categorizadas las variables, y según lo expuesto en el capítulo metodológico, se otorgó un valor de vulnerabilidad («bajo», «medio» o «alto») a cada variable (ver figura 4). Según este procedimiento, la variable que tiene un mayor porcentaje de zonas con una vulnerabilidad alta es «tipo de playa» con un $72,2 \%$. Le sigue la variable "variación de la línea de costa», que presenta un $62,6 \%$ del total en la categoría de vulnerabilidad alta. Respecto de las variables «pendiente» y "geología-geomorfología», la vulnerabilidad media es la que predomina, con un $50,7 \%$ y $51,1 \%$ respectivamente. Pasando a las variables antrópicas, se ve que en el «ancho de playa» la situación está pareja entre la vulnerabilidad media $(43,2 \%)$ y la vulnerabilidad alta $(44,4 \%)$. La situación cambia en las variables «ocupación» $\mathrm{y}$ «usos», ya que predomina la vulnerabilidad baja, con valores de $81,9 \%$ y $75 \%$ respectivamente.

A partir de la distribución espacial de los resultados antes expuestos en cifras, se puede señalar que las zonas más vulnerables en la variable "geología-geomorfología» son la desembocadura del río Jequetepeque, el balneario de Santa Elena y la playa de Puémape. En la variable «pendiente», las zonas más vulnerables son las zonas comprendidas entre La Barranca y el balneario Boca del Río, el sur del Faro en Pacasmayo y el balneario de Santa Elena. Por su parte, en el «tipo de playa», predomina la vulnerabilidad alta en casi toda la provincia. Finalmente, en la variable «variación de la línea de costa» desde el balneario de Santa Elena hasta el límite norte de la provincia, la vulnerabilidad es predominantemente alta.

La variable «ancho de playa», que intenta combinar el ancho de la playa, pero ligado principalmente a la instalación de infraestructuras en la playa permite identificar que en todas las zonas donde se encuentra instalada la población la vulnerabilidad predominante es alta o media. Por su parte, para las variables «usos del suelo» y «ocupación 
de la costa» la vulnerabilidad alta se concentra en la zona del puerto de Pacasmayo, Junco Marino, los balnearios de La Barranca, Boca del Río, El Milagro, Santa Elena y Puémape.

Figura 3. Mapa de variables antrópicas

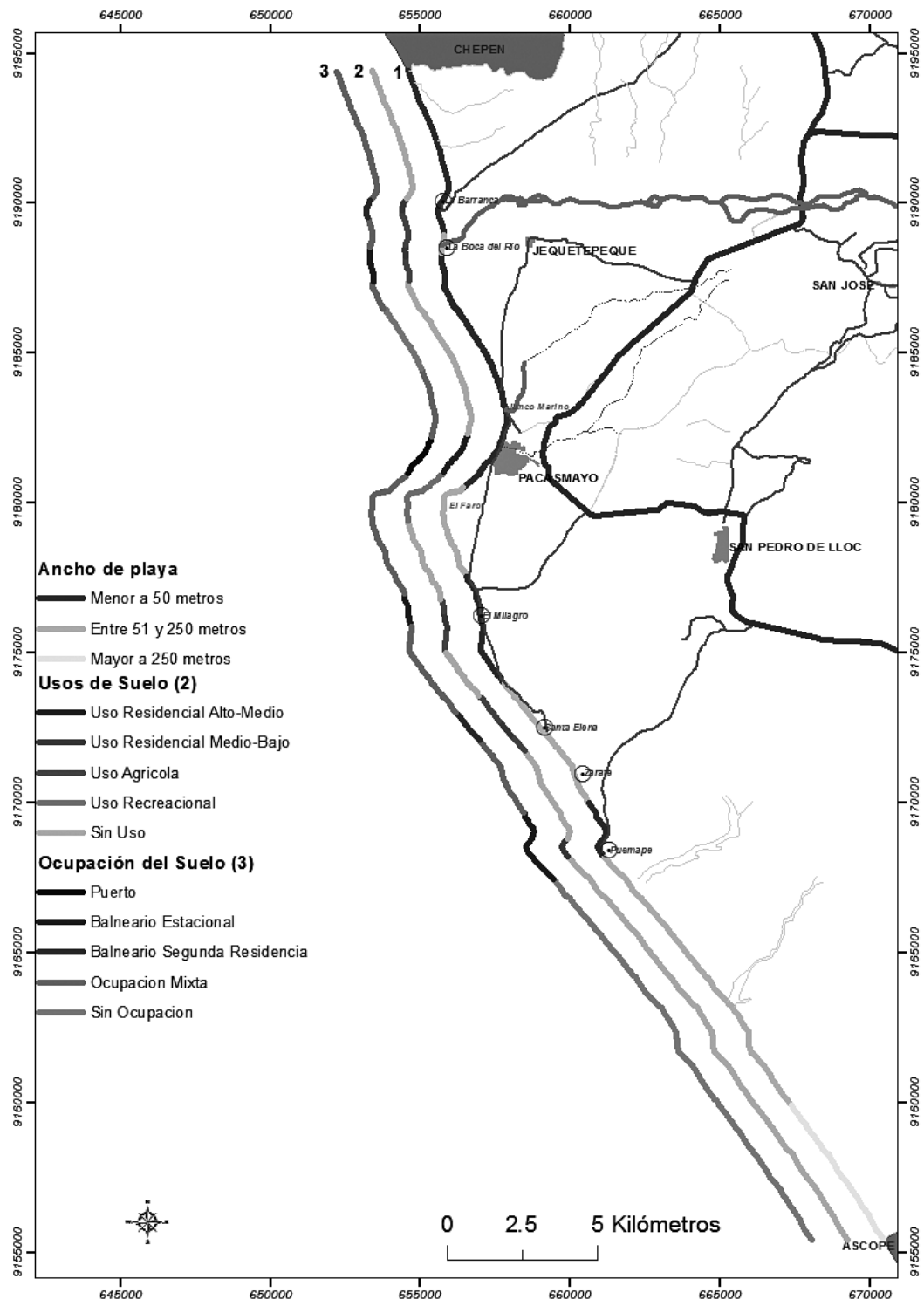

Fuentes cartográficas: Ministerio de Transportes y Comunicaciones (2015), Instituto Geográfico Nacional (2015). Elaboración propia. 
Figura 4. Mapa de vulnerabilidad para cada variable.

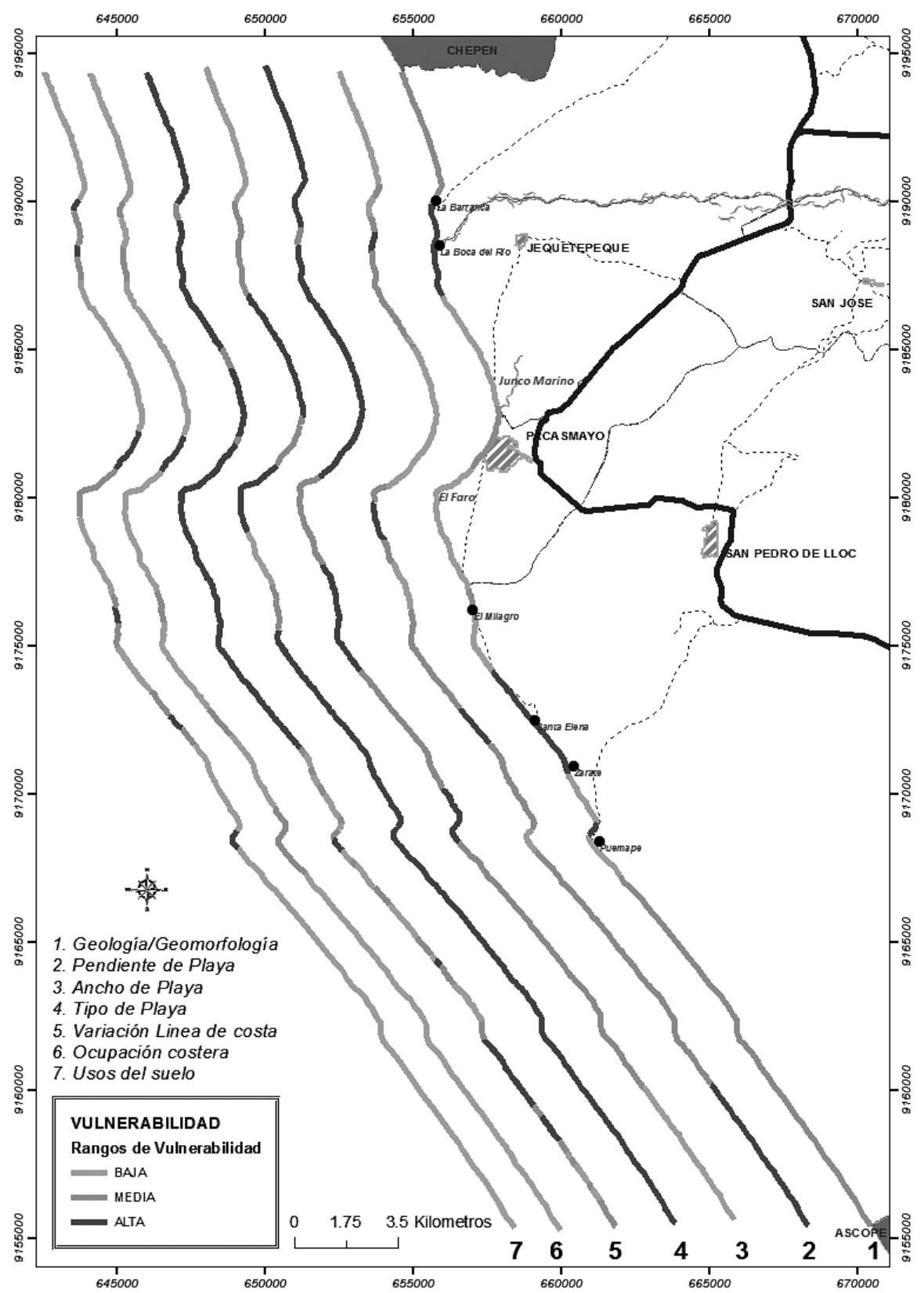

Fuentes cartográficas: Ministerio de Transportes y Comunicaciones (2015), Instituto Geográfico Nacional (2015). Elaboración propia. 
Finalmente, a partir del resultado de aplicar la ecuación 1 a los valores de cada variable (figura 5) se puede identificar que, retirando a las zonas de La Barranca y Junco Marino, son todos los balnearios y el puerto de Pacasmayo las zonas que tienen un IVC alto y solo la zona comprendida al sur de El Faro y al norte de El Milagro presenta un IVC bajo, mientras que las zonas restantes tienen un IVC medio. En cuanto a los porcentajes en la provincia de Pacasmayo, el IVC bajo representa el 5,8\%, el IVC medio el $82,9 \%$ y el IVC alto el $11,3 \%$.

Las figuras 6 y 7 permiten comparar dos IVC parciales divididos en las variables físicas y las variables antrópicas. Sin mostrar cifras, visualmente queda claro que el IVC físico presenta valores de vulnerabilidad media (65\%) y vulnerabilidad alta (32\%) predominantes. Por su parte, el IVC antrópico presenta valores predominantes en vulnerabilidad baja $(78,5 \%)$ y vulnerabilidad media $(14,1 \%)$.

Es importante analizar esto, pues al volver al mapa del IVC total y los mapas de IVC físico y antrópico queda claro que lo determinante y discriminante para el resultado final del IVC es la ocupación de la costa, ya sea por el asentamiento de la población (el puerto, los balnearios), por la ocupación (las actividades ligadas a la pesca y el turismo, las vías, etc.) o por los usos del suelo (cultivos, zonas de deportes náuticos).

\section{Discusión y Conclusiones}

La costa peruana, pese a que posee una gran extensión y que presenta una ocupación intensa en diversos sectores costeros, no solo con el asentamiento de población sino principalmente con distintas actividades económicas, concentra un número limitado de estudios dedicados en conocer su vulnerabilidad frente a la erosión costera u otras dinámicas actuales. Esta investigación buscó ser un primer acercamiento al análisis de la vulnerabilidad costera a una escala local.

La escala de trabajo implicó analizar en primer lugar variables que, a una escala local, fueran relevantes para no caer en generalidades. En segundo lugar, la escala de trabajo obligó a clasificar las categorías de cada variable en un nivel local, dejando de lado las grandes clasificaciones aplicadas por la mayoría de autores citados en las referencias metodológicas. Finalmente, y siempre respecto de la escala de trabajo, es innegable que un análisis local de algunas variables no puede ser aplicado de manera generalizada a otros sectores costeros del país. Sobre este aspecto, fue una decisión tomada pensando en que la aplicación de este IVC sea una herramienta para una correcta gestión del espacio costero de la provincia y que no busca ser un estudio comparativo con otras regiones costeras. 
Figura 5. Mapa del IVC para la provincia de Pacasmayo.

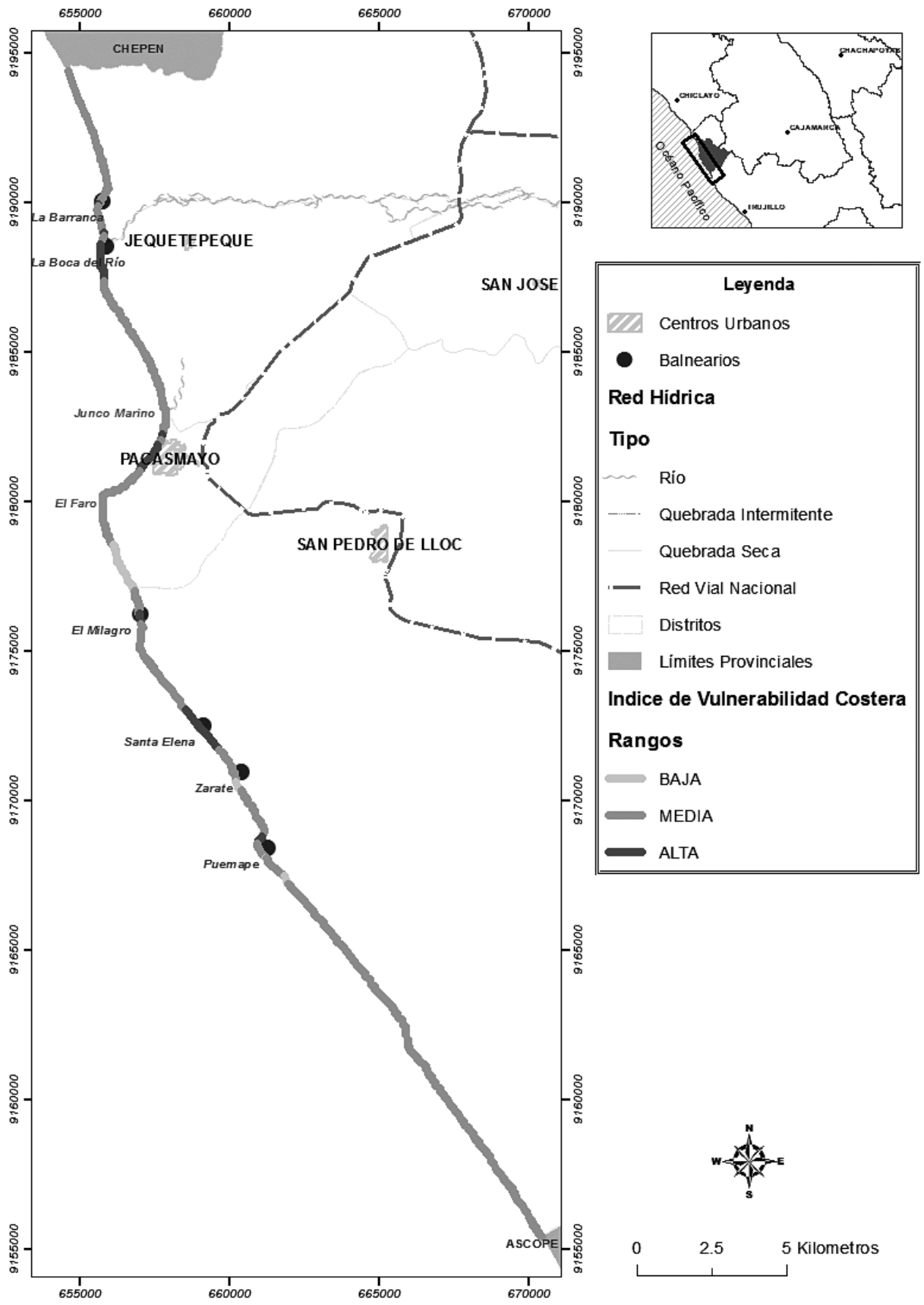

Fuentes cartográficas: Ministerio de Transportes y Comunicaciones (2015), Instituto Geográfico Nacional (2015). Elaboración propia. 
Figura 6. Mapa del IVC físico para la provincia de Pacasmayo.

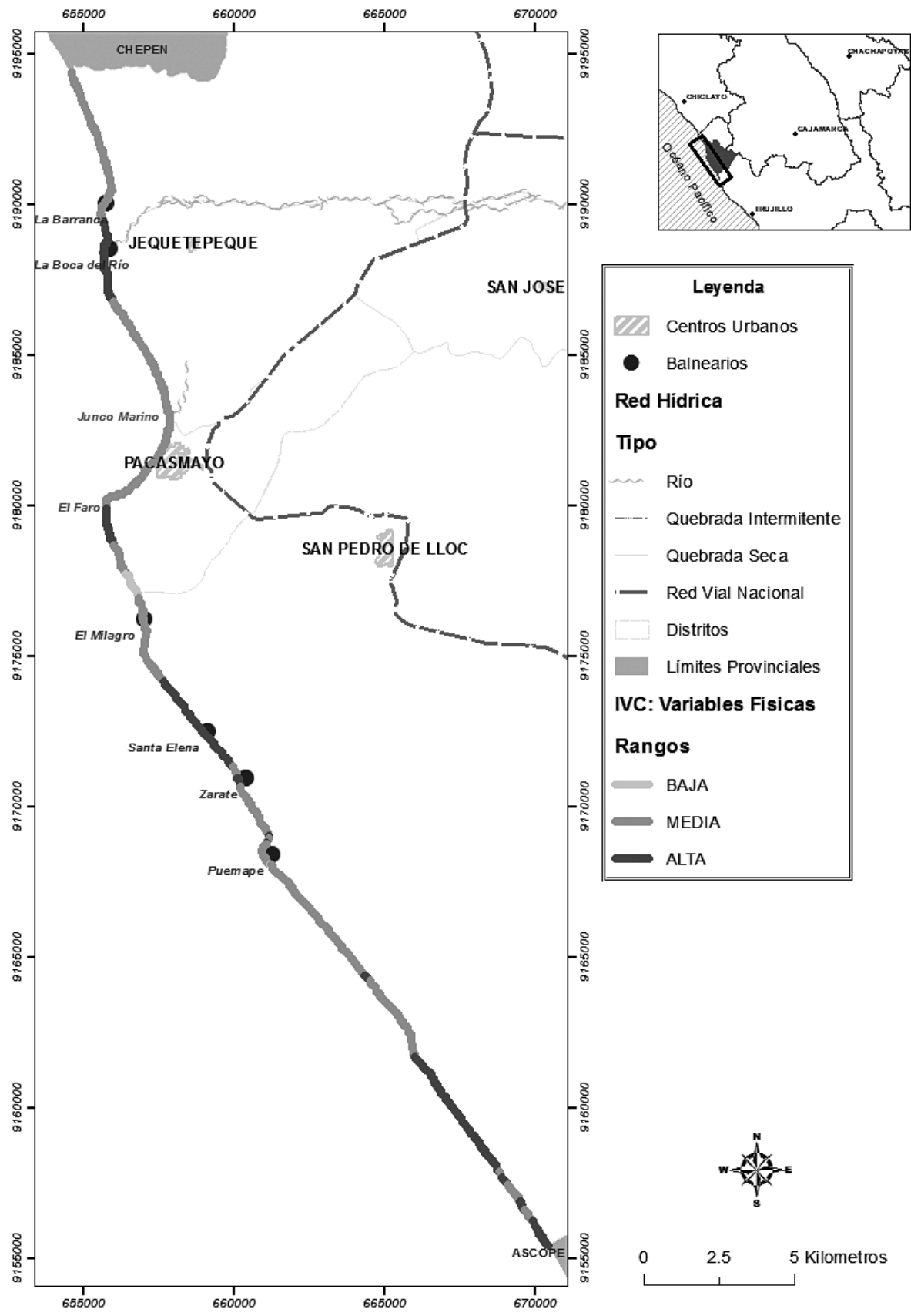


Figura 7: Mapa del IVC antrópico para la provincia de Pacasmayo.

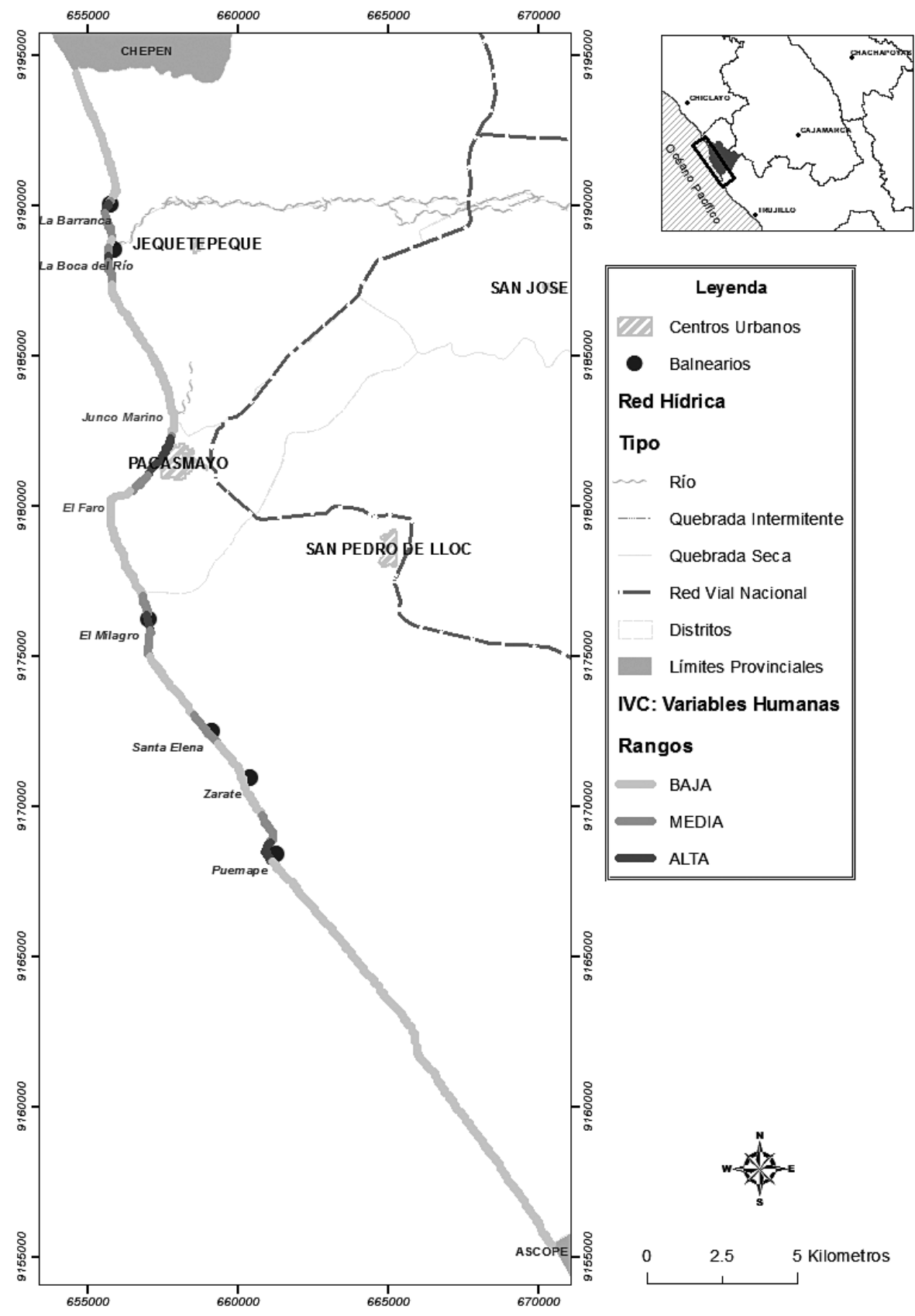

Fuentes cartográficas: Ministerio de Transportes y Comunicaciones (2015), Instituto Geográfico Nacional (2015). Elaboración propia. 
Sobre el impacto puntual del cambio climático, esta adaptación del IVC evalúa el aumento del nivel del mar en la costa peruana de manera indirecta, a través de la variación de la línea de costa. Sin embargo, como se ha desarrollado en la metodología, existen variables humanas que han sido elegidas debido a la sensibilidad que tienen con respecto al posible aumento del nivel mar: el uso de suelo o la urbanización de la costa de la provincia de Pacasmayo son variables cuya vulnerabilidad estará siempre directamente relacionada a las condiciones físicas de la costa. En este punto, es importante mencionar que la variable «variación de la línea de costa» intenta recoger una muestra local de los procesos erosivos o sedimentarios de la provincia, lo cual podría ser lo más aproximado a local para construir escenarios futuros con respecto al impacto de una subida del nivel del mar.

Evidentemente, la gran pregunta que surge luego de obtener los resultados es si estos han sido satisfactorios. Como toda investigación, la metodología elegida tiene sus pros y contras. Por ejemplo, respecto de las variables elegidas, es importante señalar que su sensibilidad para mostrar una realidad espacial del territorio ha sido muy adecuada. Las variables físicas - como la variación de la línea de costa, el tipo de playa, la pendiente y la geomorfología - describen de manera muy fina y precisa las características locales. Por ejemplo, la descripción de la geología y geomorfología local se basó en un recorrido por todo el litoral de la provincia, permitiendo enriquecer descripciones previas, como la de Teves (1982) y Tavares Corrêa (2004) que se mencionan el área de estudio. La variación de la línea de costa, por su parte, permite establecer tres categorías (erosión, estabilidad y sedimentación) para su dinámica en el tiempo, lo cual permite identificar sectores muy precisos y puntuales impidiendo generalizar la dinámica con rangos más «gruesos», que podrían llevar a clasificar todo dentro de una sola categoría de vulnerabilidad.

Esta sensibilidad de las variables físicas para describir el territorio costero de la provincia de Pacasmayo se complementa con la elección de tres variables antrópicas que, con algunos cambios mínimos, podrían ser aplicadas según las categorías establecidas en esta investigación para otras zonas costeras del país. Por ejemplo, la variable «ancho de playa» define sus tres categorías de vulnerabilidad basada en la Ley de Playas, por lo que puede ser aplicada para cualquier zona costera; la variable «usos del suelo» o la variable «ocupación de la costa» identifican grandes usos en la provincia (residencial, agrícola, etc.), que son usos muy comunes y repetidos a lo largo de la costa peruana. Por esta razón, el aporte de esta investigación, más allá de identificar la vulnerabilidad costera para la provincia de Pacasmayo, representa un primer esfuerzo por entender cómo integrar variables territoriales de naturaleza distinta en un estudio de vulnerabilidad costera a una escala local, priorizando la sensibilidad de las variables antes que la comparación con otras zonas de estudios o la réplica de las variables y sus categorías. 
Con respecto a los resultados finales del IVC, queda claro, como se ha señalado en los resultados, que son las variables antrópicas, principalmente la «ocupación de la costa» y "uso del suelo» las que determinan las zonas más vulnerables. Sin embargo, en relación con la vulnerabilidad física, la provincia de Pacasmayo está muy expuesta (vulnerabilidades alta y media). Este resultado permite a futuras gestiones del territorio dirigir bien que la ocupación costera de la provincia, teniendo en cuenta que el grado de exposición físico es alto por lo que se debe planificar bien futuras ocupaciones y expansiones de las distintas actividades antrópicas. El IVC resalta la alta vulnerabilidad a la que están expuestas las poblaciones costeras, principalmente las del puerto de Pacasmayo y los distintos balnearios (estacionales o de segunda residencia). Además, en zonas donde no hay una instalación de infraestructuras, las variables físicas muestran en el IVC total su peso e importancia (predominando zonas deshabitadas, pero con una vulnerabilidad media, por ejemplo)

Si bien, como se ha mencionado en la metodología, este análisis de las variables a una escala local puede ser un impedimento para comparar el IVC de la provincia de Pacasmayo con otros estudios (se priorizó trabajar un IVC que fuese instrumento de gestión local del territorio). Sin embargo, se ha podido realizar una comparación del resultado alcanzado del IVC al aplicar dos ecuaciones que, por un lado, solo considera la sumatoria de las variables (ecuación 1), y por otro, que calcula la raíz cuadrada del producto de las variables entre el número de variables (ecuación 2).

$$
\sqrt{\frac{a \times b \times c \times d \times e \times f \times g}{7}}
$$

De la aplicación de la ecuación 2, se desprende la siguiente clasificación:

Tabla 3. Rangos y valores para el cálculo del IVC en la provincia de Pacasmayo aplicando la ecuación 2 .

\begin{tabular}{|l|c|c|c|}
\hline Vulnerabilidad & IVC total & IVC físico & IVC antrópico \\
\hline Baja & $0,38-6,14$ & $0,5-1,8$ & $0,58-1,38$ \\
\hline Media & $6,15-11,91$ & $1,9-3,2$ & $1,39-2,19$ \\
\hline Alta & $11,92-17,68$ & $3,3-4,5$ & $2,20-3$ \\
\hline
\end{tabular}

Con esta comparación de resultados, se busca resaltar la sensibilidad que tiene la ecuación 1 con respecto a la ecuación 2. Los resultados obtenidos en la provincia de Pacasmayo con la ecuación 1 presentaron valores en el intervalo de vulnerabilidad «alta». 
Aplicando la ecuación 2, los valores máximos obtenidos en la provincia de Pacasmayo están solo en el rango de vulnerabilidad «baja» (el $52 \%$ de la costa) y en vulnerabilidad «media» ( $48 \%$ de la costa). Esto se debe a que los valores que se obtienen luego de aplicar la ecuación del producto de las variables son inferiores a 11.92, valor umbral para poder acceder al rango de vulnerabilidad «alta» (ver tabla 3 ).

Si se analiza la diferencia con respecto al resultado solo de las variables físicas obtenido mediante la ecuación 1 que se describe en «resultados», se aprecia que los valores de vulnerabilidad «media» se reducen, los de vulnerabilidad «baja» aumentan y los de vulnerabilidad «alta» se mantienen casi iguales. Con respecto al resultado solo de las variables antrópicas, con los obtenidos al aplicar la ecuación 1 se observa que la vulnerabilidad «baja» disminuye y las vulnerabilidades «media» $\mathrm{y}$ «alta» aumentan (tabla 4).

Tabla 4. Comparación de los porcentajes de línea de costa según su rango de vulnerabilidad aplicando la ecuación 1 y la ecuación 2 (\%).

\begin{tabular}{|l|c|c|c|c|c|c|}
\cline { 2 - 7 } \multicolumn{1}{c|}{} & \multicolumn{3}{c|}{ Ecuación 1 } & \multicolumn{3}{c|}{ Ecuación 2 } \\
\hline Tipo & $\begin{array}{c}\text { Vulne. } \\
\text { física }\end{array}$ & $\begin{array}{c}\text { Vulne. } \\
\text { antrópica }\end{array}$ & $\begin{array}{c}\text { Vulne. } \\
\text { total }\end{array}$ & $\begin{array}{c}\text { Vulne. } \\
\text { física }\end{array}$ & $\begin{array}{c}\text { Vulne. } \\
\text { antrópica }\end{array}$ & $\begin{array}{c}\text { Vulne. } \\
\text { total }\end{array}$ \\
\hline Alta & 32 & 7,4 & 11,3 & 29 & 11 & ------ \\
\hline Media & 65 & 14,1 & 82,9 & 31 & 33 & 48 \\
\hline Baja & 1 & 78,5 & 5,8 & 40 & 56 & 52 \\
\hline
\end{tabular}

Finalmente, comparando los resultados del IVC total, se observa que principalmente son el puerto de Pacasmayo y los balnearios (Santa Elena, El Milagro, Puémape y Boca del Río) los que pasan de ser lugares de «vulnerabilidad alta» con la ecuación 1, a ser «vulnerabilidad media» con la ecuación 2. Esto demuestra que la ecuación, usando la sumatoria de las variables, permite obtener una mayor sensibilidad para un análisis más local (integra de manera más fina lo físico y antrópico) y siempre orientando el estudio de la vulnerabilidad costera en el sentido de aportar a los procesos de gestión territorial de manera adecuada.

\section{Agradecimientos}

Los autores agradecen el apoyo de la Dirección General de Investigación - DGI de la Pontificia Universidad Católica del Perú por el financiamiento recibido para la realización de la investigación a través del Proyecto DGI 2015-1-0018, y a Fernando Gonzalez Hunt por las sugerencias para el Resumen y Abstract. 


\section{REFERENCIAS}

Abuodha, P. A. y C. D. Woodroffe (2006). International Assessments of the Vulnerability of the Coastal Zone to Climate Change, Including an Australian Perspective. Australian Greenhouse Office, Department of the Environment and Heritage.

Aguilar, M. (2015). Indice de Vulnerabilidad Costero para la Región Lima. Tesis de licenciatura. Pontificia Universidad Católica del Perú.

Appeaning Addo, K. (2013). Assessing Coastal Vulnerability Index to Climate Change: the Case of Accra - Ghana. Proceedings 12th International Coastal Symposium (Plymouth, England). Journal of Coastal Research, 65, Special Issue, 1892-1897.

Bird, E. C. F. (1985). Coastline Changes. Nueva York: Wiley and Sons.

CEPAL (2012). Efectos del cambio climático en la costa de América Latina y el Caribe. Santiago de Chile: Riesgos. Impreso en Naciones Unidas.

CESEL Ingenieros (2009). Estudio de Impacto Ambiental: Mejoramiento Integral de los Subsistemas de Almacenamiento, Distribución de Agua Potable y Sistema de Alcantarillado de la Ciudad de Pacasmayo. Lima.

Church, J. A. y N. J. White (2006). A 20th century acceleration in global sea-level rise. Geophysical Research Letters, 33(1). https://doi.org/10.1029/2005GL024826

Church, J. A. y N. J. White (2011). Sea-level rise from the late 19th to the early 21 st century. Surveys in Geophysics, 32(4-5), 585-602. https://doi.org/10.1007/s10712-011-9119-1

Consejería de Medio Ambiente. Junta de Andalucía (2011). Análisis preliminar de la vulnerabilidad de la costa de Andalucía a la potencial subida del nivel del mar asociado al cambio climático. Andalucía: Fondo de Desarrollo Europeo.

Doukakis, E. (2005). Coastal Vulnerability and Risk Parameters. European Water, 11/12, 3-7.

Dwarakish, G. S., S. A. Vinay, Usha Natesan, Toshiyuki Asano, Taro Kakinuma, Katta Venkataramana, B. Jagadeesha y M. K. Babita (2009). Coastal vulnerability assesment of the future sea level rise in Udupi coastal zone of Karnataka state, west coast of India. Ocean and Coastal Management, 52, 467-478. https://doi.org/10.1016/j. ocecoaman.2009.07.007

European Environment Agency (2011). Methods for assessing coastal vulnerability to climate change. Bolonia: European Topic Centre on Climate Change Impacts, Vulnerability and Adaptation c/o Centro Euro-Mediterraneo per i Cambiamenti Climatici - CMCC.

FAO (2012). Estado de las áreas marinas y costeras protegidas en América Latina. Elaborado por Aylem Hernández Ávila. Santiago de Chile: REDPARQUES Cuba.

González, D., M. Haces y L. Rangel (2010). Metodología para valorar indices de vulnerabilidad ante el cambio climático y acciones de compensación en las costas de Tamaulipas. Tampico: Universidad Autónoma de Tamaulipas, Centro Universitario Tampico-Madero. 
Gornitz, V. (1991). Global coastal hazards from future sea level rise. Palaeogeography, Palaeoclimatology, Palaeoecology (Global and Planetary Change Section), 89, 379-398. Ámsterdam: Elsevier Science Publishers B.V. https://doi.org/10.1016/0031-0182(91) 90173-O

Gornitz, V., T. Beaty, R. Daniels (1997). A coastal hazards database for the U.S West Coast. Environmental Sciences Division. Publication N ${ }^{\circ}$ 4590. U.S Department of Energy. Gorokhovich, Y., A. Leiserowitz y D. Dugan (2014). Integrating Coastal Vulnerability and Community-Based Subsistence Resource Mapping in Northwest Alaska. Journal of Coastal Research, 30(1), 158-169. Florida: Coconut Creek. https://doi.org/10.2112/ JCOASTRES-D-13-00001.1

Green, C. y L. Mcfadden (2007). Coastal vulnerability as discourse about meanings and values. Journal of Risk Research, 8(10), 1027-1045. https://doi.org/10.1080/ 13669870701566557

Hammar-Klose E. S., E. A. Pendleton, E. R. Thieler y S. J. Williams (2003). Coastal Vulnerability Assessment of Cape Cod National Seashore (CACO) to Sea-Level Rise. U.S. Geological Survey. Open file Report 02-233.

IPCC (2014). Climate Change 2014: Impacts, Adaptation, and Vulnerability. Part A: Global and Sectoral Aspects. Contribution of Working Group II to the Fifth Assessment Report of the Intergovernmental Panel on Climate Change [C. B. Field, V. R. Barros, D. J. Dokken, K. J. Mach, M. D. Mastrandrea, T. E. Bilir, M. Chatterjee, K. L. Ebi, Y. O. Estrada, R. C. Genova, B. Girma, E. S. Kissel, A. N. Levy, S. MacCracken, P. R. Mastrandrea y L. L. White (eds.)]. Nueva York: Cambridge University Press, Cambridge, United Kingdom and New York.

Jiménez, J. (2013). Vulnerabilidad costera al impacto de tormentas. Barcelona: Universitat Politécnica de Catalunya, Laboratori d'Enginyeria Marítima.

Kokot, R., J. Codignotto and M. Elissondo (2004). Vulnerabilidad al ascenso del Nivel del mar en la costa de la provincia de Río Negro. Asociación Geológica Argentina, 59(3), 477-487.

Ley 26856 (1997). Declara que las playas del litoral son bienes de uso público, inalienables e imprescriptibles y establecen zona de dominio restringido. Diario Oficial El Peruano, 08/09/1997.

McLaughlin, S., J. McKenna, J. Cooper (2002). Socio-economic data in coastal vulnerability indices: constraints and opportunities. Journal of Coastal Research, Special Issue 36, 487-497. https://doi.org/10.2112/1551-5036-36.sp1.487

Merlotto, A., G. Bértola y M. Piccolo (2011). Riesgo a la erosión costera en las ciudades de Necochea y Quequén, provincia de Buenos Aires, Argentina. Contribuciones Cientificas GAA, 23, 151-158. 
Ministerio de Ambiente de España (2006). Impactos en la costa española por efecto del cambio climático. Cantabria: Dirección General de Calidad y Evaluación Ambiental y Universidad de Cantabria.

Municipalidad Provincial de Pacasmayo (2008). Plan de desarrollo concertado de la provincia de Pacasmayo. Pacasmayo: s.e.

Nageswara, K., P. Subraelu, T. Venkateswara, B. Hema, R. Ratheesh, S. Bhattacharya, A. Rajawat, AJAI (2008). Sea-level rise and coastal vulnerability: an assessment of Andhra Pradesh coast, India through remote sensing and GIS. Journal of Coastal Conservation, 12(4), 195-207.

Novoa, Z. (2007). Geografia de las zonas marino-costeras: el litoral pacifico peruano. Lima: Sociedad Geográfica de Lima.

Ojeda, J., J. Álvarez, D. Martín y P. Fraile (2008). El uso de las TIG para el cálculo del Índice de Vulnerabilidad Costera (CVI) ante una potencial subida del nivel del mar en la costa andaluza. En Tecnologías de la Información Geográfica para el Desarrollo Territorial (pp. 660-671). Las Palmas de Gran Canaria: Universidad de las Palmas de Gran Canaria.

Pendleton, E. A., E. S. Hammer-Klose, E. R. Thieler y S. J. Williams (2004). Coastal Vulnerability Assessment of Gulf Islands National Seashore (GUIS) to Sea Level Rise. U.S. Geological Survey Open-File 03-108, 18 p. http://pubs.usgs.gov/of/2003/of03-108/.

Ramírez, E. (2010). Estimación de la vulnerabilidad costera ante amenazas hidrometeorológicas de la franja Tijuana-Ensenada. Tesis de maestría. Universidad de Tijuana, México.

Ronald, W. (2012). Applying a Coastal Vulnerability Index (CVI) to the Westfjords, Iceland: a preliminary assessment. Tesis de maestría. Akureyri, Islandia: University of Akureyri, Faculty of Business and Science University Centre of the Westfjords.

Sarajit, O., K. Nakhapakorn, S. Jirakajohnkool, K. Tienwong y A. Pansuwan (2015). Assessing Coastal Composite Vulnerability Indices on Seasonal Change in Phetchaburi, Thailand. EnvironmentAsia, 8, 115-123. https://doi.org/10.14456/ea.2015.14.

Siva, T., A. Chandramouli, K. Gokul, S. Mangala y J. Saravanavel (2015). Coastal Vulnerability Mapping Using Geospatial Technologies in Cuddalore-Pichavaram Coastal Tract, Tamil Nadu, India. International Conference on Water Resources, Coastal and Ocean Engineering. Aquatic Procedia, 4, 412-418. https://doi.org/ 10.1016/j. aqpro.2015.02.055

Sousa, P., E. Siegle y M. Gonsalez (2013). Vulnerability assessment of Massaguaçú Beach (SE Brazil). Ocean and Coastal Management, 77, 24-30. https://doi.org/10.1016/j. ocecoaman.2012.03.003

Tavares Corrêa, C. (2004). El continuum dunario y el manejo de dunas litorales en el norte del Perú. Boletín de la Sociedad Geográfica de Lima, 113(117), 171-180. 
Tavares Corrêa, C. y G. Rondón (2015). Impacto de la represa de Gallito Ciego en la estabilidad de línea de costa en la desembocadura del río Jequetepeque, Perú. Espacio y Desarrollo, 27, 79-101. https://doi.org/10.18800/espacioydesarrollo.201501.004

Tejeda, R. X. (2017). Análisis de la vulnerabilidad costera frente a un posible aumento del nivel del mar: sector costero Lurín - Pucusana (Provincia de Lima). Tesis de licenciatura. Pontificia Universidad Católica del Perú.

Teves, N. (1982). Geomorfología del sector costanero comprendido entre los ríos Jequetepeque y Chamán. Boletin de la Sociedad Geológica del Perú, 69, 71-82.

Teves, N., G. Laos, S. Carrasco, C. San Román, L. Pizarro, G. Cárdenas y A. Romero (1996a). Sea-level rise along the Lima Coastal Zone, Peru, as a result of global warming: environmental impacts and mitigation measures. En J. Smith, N. Bhatti, G. Menzhulin, R. Benioff, M. I. Budyko, M. Campos, B. Jallow y F. Rijsberman (eds.), Adapting to Climate Change: An International Perspective (pp. 283-298). New York: Springer-Verlag.

Teves, N., G. Laos, S. Carrasco, C. San Román y L. Clemente (1996b). Vulnerability and Adaptation Assessments for Peru. En J.B. Smith, S. Huq, S. Lenhart, L.J. Mata, I. Nemešová y S. Toure (eds.), Vulnerability and Adaptation to Climate Change (pp. 335-345). The Netherlands: Kluwer Academic Publishers. https://doi. org/10.1007/978-94-017-3653-4_16

Torresan, S., A. Critto, J. Rizzi, A. Marcomini (2012). Assessment of coastal vulnerability to climate change hazards at the regional scale: the case study of the North Adriatic Sea. Nat. Hazards Earth Syst. Sci., 12, 2347-2368. https://doi.org/10.5194/nhess12-2347-2012

Zhang, K., B. Dogulas y S. Letherman (2004). Global Warming and Coastal Erosion. Climate Change, 64, 41-58.

\section{Fuente cartográficas}

Ministerio de Transportes y Comunicaciones (2015). Shapefiles límites administrativos, vías y áreas urbanas.

Instituto Geográfico Nacional (2015). Shapefiles de centros poblados, curvas de nivel y red hídrica. 